\title{
The two-component system BfrAB regulates expression of $A B C$ transporters in Streptococcus gordonii and Streptococcus sanguinis
}

\begin{abstract}
Correspondence
Mark C. Herzberg

mcherzb@umn.edu
\end{abstract}

Received 8 August 2008

Revised 14 October 2008

Accepted 16 October 2008
Yongshu Zhang, ${ }^{1}$ Marvin Whiteley, ${ }^{2}$ Jens Kreth, ${ }^{1}$ Yu Lei, ${ }^{1}$ Ali Khammanivong, ${ }^{1}$ Jamie N. Evavold, ${ }^{1}$ Jingyuan Fan ${ }^{1}$ and Mark C. Herzberg ${ }^{1,3}$

\author{
${ }^{1}$ Department of Diagnostic and Biological Sciences, School of Dentistry, University of Minnesota, \\ Minneapolis, MN 55455, USA \\ ${ }^{2}$ Section of Molecular Genetics and Microbiology, the University of Texas at Austin, Austin, \\ TX 78712, USA \\ ${ }^{3}$ Mucosal and Vaccine Research Center, Minneapolis VA Medical Center, Minneapolis, MN 55417, \\ USA
}

The putative two-component system BfrAB is involved in Streptococcus gordonii biofilm development. Here, we provide evidence that $\mathrm{Bfr} A \mathrm{~B}$ regulates the expression of $b f \mathrm{C} D$ and bfrEFG, which encode two ATP-binding cassette (ABC) transporters, and $b f r H$, which encodes a CAAX amino-terminal protease family protein. BfrC and BfrE are ATP-binding proteins, and BfrD, $\mathrm{BfrF}$ and $\mathrm{BfrG}$ are homologous membrane-spanning polypeptides. Similarly, BfrAB $\mathrm{B}_{\mathrm{ss}}$, the BfrAB homologous system in Streptococcus sanguinis, controls the expression of two bfrCDhomologous operons ( $b f r C D_{\text {ss }}$ and $\left.b f r X Y_{\mathrm{ss}}\right)$, a $b f r H$-homologous gene $\left(b f r H 1_{\text {ss }}\right)$ and another CAAX amino-terminal protease family protein gene $\left(b f r H 2_{s s}\right)$. Furthermore, we demonstrate that the purified BfrA DNA-binding domain from S. gordonii binds to the promoter regions of $b f C D$, bfrEFG, bfrH, bfrCD $D_{\mathrm{ss}}, b f r X Y_{\mathrm{ss}}$ and $b f r H 1_{\text {ss }}$ in vitro. Finally, we show that the BfrA DNA-binding domain recognizes a conserved DNA motif with a consensus sequence of

TTTCTTTAGAAATATTTTAGAATT. These data suggest, therefore, that $S$. gordonii BfrAB controls biofilm formation by regulating multiple $A B C$-transporter systems.

\section{INTRODUCTION}

Dental plaque is a polymicrobial biofilm on the salivacoated tooth surface that can cause caries, gingivitis and periodontal diseases (Rosan \& Lamont, 2000). Streptococcus gordonii is a pioneer colonizer of dental plaque, preferentially adhering to cleaned saliva-coated tooth surfaces (Nyvad \& Kilian, 1987, 1990). S. gordonii also colonizes other oral sites and is not normally harmful in the human oral cavity (Frandsen et al., 1991; Socransky et al., 1998). When introduced into the blood, however, $S$. gordonii, like other oral streptococci, can be involved in the development of infective endocarditis (Bayliss et al., 1983; Herzberg, 1996; Manford et al., 1992).

Abbreviations: ABC, ATP-binding cassette; EMSA, electrophoretic mobility shift assay; TCS, two-component system.

The array data discussed in this paper have been deposited in MIAMEXPRESS (http://www.ebi.ac.uk/microarray) and are accessible through accession number E-MEXP-1712.

A supplementary table listing primers used in this work is available with the online version of this paper.
To colonize several intraoral sites or to enter the circulating blood and infect heart valves, oral streptococci must adapt to environmental changes. Gene regulation by twocomponent systems (TCSs) is a common mechanism used by bacteria to modulate cell behaviour in response to environmental changes (Stock et al., 2000). TCSs are involved in the regulation of biofilm development in several species, including Escherichia coli (Dorel et al., 1999; Otto \& Silhavy, 2002; Prigent-Combaret et al., 1999), Pseudomonas aeruginosa (Parkins et al., 2001), Staphylococcus aureus (Fournier \& Hooper, 2000; ToledoArana et al., 2005), Streptococcus mutans (Bhagwat et al., 2001; Li et al., 2002; Shemesh et al., 2007) and Enterococcus faecalis (Hancock \& Perego, 2004). A TCS is typically composed of a histidine kinase and a response regulator. The response regulator generally acts to regulate transcription. After detection of the environmental signal, the histidine kinase undergoes autophosphorylation of a conserved histidine residue. The phosphoryl group is subsequently transferred to a conserved aspartate residue of a cognate response regulator. Aspartate phosphorylation 
of the response regulator alters the binding affinity for target sites and leads to changes in gene expression.

In S. gordonii, the TCS ComDE is involved in competence, regulating DNA uptake (Havarstein et al., 1996; Lunsford, 1998), and is required for biofilm formation in vitro (Loo et al., 2000). The signal is a secreted competencestimulating peptide (CSP), encoded by $\operatorname{com} C$, which is a member of a three-gene operon comCDE. The extracellular CSP binds the histidine kinase ComD, which subsequently phosphorylates the response regulator ComE. ComE transcriptionally regulates expression of over 100 genes (Vickerman et al., 2007).

We previously characterized the role of a TCS, BfrAB, in $S$. gordonii biofilm development (Zhang et al., 2004). In the present study we identify genes regulated by the BfrAB TCS in S. gordonii. Using DNA microarray analysis, RT-PCR and electrophoretic mobility shift assays (EMSAs), we show that under the tested conditions, BfrAB regulates the expression of $b f r C D$ and $b f r E F G$ operons, which encode two ATP-binding cassette $(\mathrm{ABC})$ transporters, and one additional gene $b f r H$, which encodes a homologue to the CAAX amino-terminal protease family. We also provide evidence that $b f r A B$ and $b f r A B$-homologous systems share common roles as regulators of $b f r C D$ and $b f r C D$-homologous operons in S. gordonii and Streptococcus sanguinis. These results suggest that $\mathrm{Bfr} \mathrm{AB}$ controls biofilm formation by regulating multiple $\mathrm{ABC}$-transporter systems.

\section{METHODS}

Bacterial strains and culture conditions. Strains of $S$. gordonii V288 and S. sanguinis SK36 (listed in Table 1) were routinely grown in chemically defined synthetic medium (FMC) (Terleckyj \&
Shockman, 1975; Terleckyj et al., 1975) at $37{ }^{\circ} \mathrm{C}$ in $5 \% \mathrm{CO}_{2}$. E. coli $\mathrm{DH} 5 \alpha$ cells were grown aerobically at $37{ }^{\circ} \mathrm{C}$ in Luria-Bertani (LB) medium. When required, antibiotics were added to the medium at the following concentrations: erythromycin (Em), $10 \mu \mathrm{g} \mathrm{ml}^{-1}(S$. gordonii and S. sanguinis); kanamycin $(\mathrm{Km}), 50 \mu \mathrm{g} \mathrm{ml}^{-1}$ (E. coli), $250 \mu \mathrm{g} \mathrm{ml}^{-1}$ (S. gordonii and S. sanguinis); and tetracycline (Tc) $10 \mu \mathrm{g} \mathrm{ml}^{-1}$ (S. gordonii).

Genetic manipulations. Standard recombinant DNA techniques were employed as described by Sambrook et al. (1989). Plasmids (listed in Table 1) were purified from E. coli cells using the QIAquick Spin Miniprep Purification kit (Qiagen). Chromosomal DNA was prepared as described previously (Zhang et al., 2004). Oligonucleotides (see Supplementary Table S1) were synthesized by Integrated DNA Technologies. PCR products were purified using the High Pure PCR Product Purification kit (Roche). DNA restriction and modification enzymes were used as specified by the manufacturer (Promega).

The bfrAB operons of S. gordonii V288 and S. sanguinis SK36 were inactivated by allelic exchange with the erythromycin-resistance determinant ermAM. ermAM was amplified from plasmid pVA891 (Macrina et al., 1983) and cloned into pPCR-Amp SK (+) (Stratagene). Two DNA fragments constituting the flanking sequences of the $b f r$ operons were then amplified and fused with the ermAM genes sequentially (Nobbs et al., 2007). The fused construct was then PCR-amplified, purified and transformed into S. gordonii V288 or S. sanguinis SK36 as described previously (Tao \& Herzberg, 1999), generating the deletion mutants S. gordonii V288 $\mathrm{ffr}^{-}$and S. sanguinis SK36 bfr ${ }^{-}$. The insertions were confirmed by PCR amplification and sequencing.

To complement the $b f r A B$ deletion mutant, a DNA fragment encompassing the entire $b f r A B$ operon was amplified by PCR and cloned into the E. coli-streptococcal shuttle vector pDL276 (Dunny et al., 1991). The construct was amplified in E. coli, purified, and used to transform the $S$. gordonii V288 $\mathrm{bfr}^{-}$mutant to obtain the complemented strain V288 $b \mathrm{fr}^{+}$. Predicted insertions were confirmed by PCR amplification and sequencing. Complementation was confirmed by detection of the $b f r$ RNA transcript. The complemented strain of $S$. sanguinis, SK36bfr ${ }^{+}$, was constructed using the same method.

Table 1. Bacterial strains and plasmids used in this study

\begin{tabular}{|c|c|c|}
\hline Strain or plasmid & Relevant characteristics ${ }^{*}$ & Source or reference \\
\hline \multicolumn{3}{|l|}{ E. coli strain } \\
\hline $\mathrm{DH} 5 \alpha \mathrm{F}^{\prime} \mathrm{I}^{\mathrm{q}}$ & $\begin{array}{c}\mathrm{F}^{\prime} \operatorname{proA}^{+} B^{+} \operatorname{lacl}^{q} \Delta(\text { lacZ }) M 15 \text { zzf: }: \operatorname{Tn} 10\left(\mathrm{Tet}^{\mathrm{R}}\right) / \mathrm{fhuA} 2 \Delta(\arg F-\operatorname{lac} Z) U 169 \\
\text { phoA glnV44 } \phi 80 \Delta(\text { lacZ) M15 gyrA96 recA1 relA1 endA1 thi-1 hsdR17 }\end{array}$ & New England Biolabs \\
\hline \multicolumn{3}{|l|}{ S. gordonii strains } \\
\hline V288 & Wild-type & G. Dunny, University of Minnesota \\
\hline MG288-1015 & bfraB:: tet $\left(\mathrm{Tc}^{\mathrm{R}}\right)$ & Zhang et al. (2004) \\
\hline $\mathrm{V} 288 \mathrm{bfr}^{-}$ & $\Delta(b f r A B):: \operatorname{erm} A M\left(\mathrm{Em}^{\mathrm{R}}\right)$ & This study \\
\hline $\mathrm{V} 288 b f r^{+}$ & $\Delta(b f r A B):: \operatorname{erm} A M(\mathrm{pDL} 276 b f r A B)\left(\mathrm{Em}^{\mathrm{R}}, \mathrm{Km}^{\mathrm{R}}\right)$ & This study \\
\hline \multicolumn{3}{|l|}{ S. sanguinis strains } \\
\hline SK36 & Wild-type & Kilian \& Holmgren (1981) \\
\hline SK36bfr ${ }^{-}$ & $\Delta\left(s s A \_0401-402\right)::$ ermAM $\left(\mathrm{Em}^{\mathrm{R}}\right)$ & This study \\
\hline SK $36 b f r^{+}$ & $\Delta\left(s s A \_0401-402\right)::$ ermAM $\left(\mathrm{pDL} 276 s s A \_0401-402\right)\left(\mathrm{Em}^{\mathrm{R}}, \mathrm{Km}^{\mathrm{R}}\right)$ & This study \\
\hline \multicolumn{3}{|c|}{ 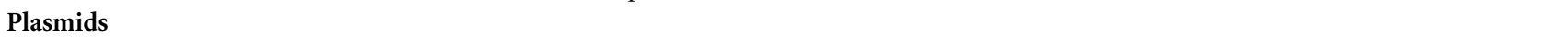 } \\
\hline pPCR-Amp SK $(+)$ & $3.0 \mathrm{~kb} ; \mathrm{Ap}^{\mathrm{R}} ; \mathrm{pUCori}$ & Stratagene \\
\hline pDL276 & $6.9 \mathrm{~kb} ; \mathrm{Km}^{\mathrm{R}}$; ColE1 ori, E. coli-streptococcal shuttle vector & Dunny et al. (1991) \\
\hline pVA891 & $5.4 \mathrm{~kb} ; \mathrm{Em}^{\mathrm{R}}, \mathrm{Cm}^{\mathrm{R}}$; pACYCori, E. coli-streptococcal shuttle vector & Macrina et al. (1983) \\
\hline pQE80L & $4.7 \mathrm{~kb} ; \mathrm{Ap}^{\mathrm{R}}$; ColE1ori, E. coli expression vector & Qiagen \\
\hline
\end{tabular}


RNA extraction and cDNA synthesis. RNA extraction from bacterial cultures, confirmation of RNA integrity and estimation of purity on agarose gels, and cDNA synthesis were performed as described previously (Zhang et al., 2004, 2005). For each RNA sample, a control cDNA reaction in the absence of reverse transcriptase was performed to check for DNA contamination.

DNA microarray design, cDNA labelling and hybridization. Fresh FMC medium containing appropriate antibiotics was inoculated with $10 \%$ of the overnight cultures of S. gordonii strains and incubated at $37{ }^{\circ} \mathrm{C}$ in $5 \% \mathrm{CO}_{2}$. After $6 \mathrm{~h}$, bacterial cells reached early stationary phase $\left(\mathrm{OD}_{620} \sim 1.8\right)$. RNA was then isolated. DNA contamination was assessed by PCR amplification of the clpX gene, and RNA integrity was monitored by agarose gel electrophoresis of glyoxylated samples (Ambion). RNA was prepared for hybridization to a custom $S$. gordonii Affymetrix GeneChip microarray as previously described (Brown \& Whiteley, 2007; Palmer et al., 2005). Probes for the GeneChip were designed for each ORF using the $S$. gordonii genome sequence available at http://www.ncbi.nlm.nih.gov (probe sequences available from the authors). Washing, staining and scanning of the GeneChips was performed at the University of Iowa DNA Core Facility using an Affymetrix Fluidics Station. GeneChips were hybridized in duplicate for each condition. Data analysis was performed using GeneChip Operating Software version 1.4 to compare between two conditions, and genes were reported as differentially regulated $(P \leqslant 0.05, n=2)$ based on pairwise statistical analysis as described previously (Brown \& Whiteley, 2007).

Semiquantitative PCR. To compare the specific gene expression levels among the wild-type S. gordonii V288, V288 $\mathrm{ffr}^{-}$and V288 $\mathrm{ffr}^{+}$, and among the wild-type S. sanguinis SK36, SK36bfr ${ }^{-}$and SK36 bfr ${ }^{+}$, semiquantitative RT-PCR (Nambu et al., 2003) was used. Fourfold serial dilutions $(1: 4,1: 16,1: 64$ and $1: 256)$ of cDNA were prepared in deionized water. Each PCR was performed in a total volume of $25 \mu$ containing $1 \times$ Green GoTaq Flexi Buffer (Promega), $0.2 \mathrm{mM}$ of each dNTP, $1.0 \mu \mathrm{M}$ of each upstream primer and downstream primer, GoTaq DNA polymerase (Promega) and $3 \mu$ diluted cDNA. The 16S rRNA gene was used as an internal control for RT-PCR as reported previously (Zhang et al., 2005). The PCR conditions for protein-encoding genes were (i) $95{ }^{\circ} \mathrm{C}$ for $5 \mathrm{~min}$; (ii) 30 cycles of $94{ }^{\circ} \mathrm{C}$ for $30 \mathrm{~s}, 55{ }^{\circ} \mathrm{C}$ for $30 \mathrm{~s}$, and $72{ }^{\circ} \mathrm{C}$ for $30 \mathrm{~s}$; and (iii) $72{ }^{\circ} \mathrm{C}$ for $4 \mathrm{~min}$. Sixteen amplification cycles were performed for the PCR of the $16 \mathrm{~S}$ rRNA gene. The PCR products $(5 \mu \mathrm{l})$ were analysed on $1.7 \%$ agarose gels and stained with ethidium bromide.

Expression and purification of the DNA-binding domain of BfrA. The DNA fragment (327 bp) encoding the DNA-binding domain of BfrA was amplified by PCR. The PCR products were digested with BamHI and Sall, ligated into the BamHI/SalI sites within the expression vector $\mathrm{PQE80L}$ (Qiagen) in the reading frame of the $5^{\prime}$ (His) ${ }_{6}$-encoding sequence, and transformed into NEB DH5 $\alpha$ $\mathrm{F}^{\prime} \mathrm{I}^{\mathrm{q}}$ competent $E$. coli cells (New England Biolabs). The construct was confirmed by DNA sequencing. The resulting cells were cultured in $\mathrm{LB}$ medium until growth reached $\mathrm{OD}_{600} \sim 0.5-0.6$. In these cultures, expression of the His-tagged DNA-binding domain of BfrA ( $\mathrm{His}_{6} \mathrm{DBBfrA}$ ) was induced by incubation with $1 \mathrm{mM}$ IPTG for $4 \mathrm{~h}$ at $37^{\circ} \mathrm{C}$. Cells were lysed and inclusion bodies were isolated using BPER Bacterial Protein Extraction Reagent (Pierce) following the manufacturer's instructions. The isolated inclusion bodies were dissolved in $6 \mathrm{M}$ guanidine hydrochloride and purified using a NiNTA Superflow column (Qiagen) under denaturing conditions, as described in The QIAexpressionist, fifth edition (Qiagen). The peak fractions were adjusted to $\mathrm{pH} 8.0$ by $1 \mathrm{M}$ Tris base. The refolding buffers were first optimized using the Protein Refolding kit (Athena Environmental Sciences). The refolding was then performed in the selected buffer $(50 \mathrm{mM}$ Tris/ $\mathrm{HCl}, \mathrm{pH} 8.5,9.6 \mathrm{mM} \mathrm{NaCl}, 0.4 \mathrm{mM}$
$\mathrm{KCl}, 1 \mathrm{mM}$ EDTA, $0.5 \%$ Triton X-100 and $1 \mathrm{mM}$ DTT) following the manufacturer's instructions.

EMSA. A non-isotopic EMSA kit (Molecular Probes) was used to test the interactions of the $\mathrm{His}_{6} \mathrm{DBBfrA}$ and the upstream promotercontaining regions of the target genes. The upstream intergenic regions of the target genes were amplified by PCR. The purified PCR product $\left(40 \mathrm{ng}\right.$ ) was then mixed with the refolded $\mathrm{His}_{6} \mathrm{DBBfrA}$ in $1 \times$ binding buffer (10 mM Tris/ $\mathrm{HCl}, \mathrm{pH} 8.0,50 \mathrm{mM} \mathrm{KCl}, 0.5 \mathrm{mM}$ DTT, $0.05 \mathrm{mM}$ EDTA, $1 \mathrm{mM} \mathrm{MgCl} 2$ and $5 \%$, v/v, glycerol) in a total reaction volume of $20 \mu \mathrm{l}$. The mixture was incubated for $30 \mathrm{~min}$ at room temperature and then mixed with $4 \mu \mathrm{l} 6 \times$ loading buffer. The DNA-protein complexes $(20 \mu \mathrm{l}$ per lane) were then examined by electrophoresis using $5 \%$ nondenaturing polyacrylamide gels stained with SYBR Green and visualized using a $314 \mathrm{~nm}$ UV transilluminator following the manufacturer's protocol.

An isotopic EMSA was used to test for interactions of $\mathrm{His}_{6} \mathrm{DBBfrA}$ with the synthesized double-strand DNA probes. The probes were $5^{\prime}$ end-labelled with $\left[\gamma^{32} \mathrm{P}\right]$ ATP by T4 polynucleotide kinase (Promega) and purified using Mini Quick Spin Oligo Spin Columns (Roche). ${ }^{32}$ P-labelled probes $(10000$ c.p.m.) were mixed with the refolded His $_{6}$ DBBfrA in $1 \times$ binding buffer $(10 \mathrm{mM}$ Tris/ $\mathrm{HCl}, \mathrm{pH} 8.0,50 \mathrm{mM}$ $\mathrm{KCl}, 0.5 \mathrm{mM}$ DTT, $0.05 \mathrm{mM}$ EDTA, $1 \mathrm{mM} \mathrm{MgCl}_{2}, 5 \%$, v/v, glycerol, $0.025 \mathrm{mg}$ poly $(\mathrm{dI}-\mathrm{dG}) \mathrm{ml}^{-1}$ and $0.5 \mathrm{mg} \mathrm{BSA} \mathrm{ml}^{-1}$ ) in a total reaction volume of $20 \mu \mathrm{l}$. In a competition binding assay, $6 \mathrm{pmol}$ of the unlabelled competitor DNA probe or noncompetitor probe was added. The mixture was incubated for $30 \mathrm{~min}$ at room temperature and then mixed with $4 \mu \mathrm{l} 6 \times$ loading buffer. The DNA-protein complexes (20 $\mu \mathrm{l}$ per lane) were then examined by electrophoresis using $8 \%$ nondenaturing polyacrylamide gels and visualized by autoradiography.

Gene sequences. The annotated genomes of $S$. gordonii (NC_009785) and S. sanguinis (NC_009009) are available at http://www.ncbi.nlm.nih.gov.

\section{RESULTS}

\section{Identification of genes regulated by the BfrAB TCS in S. gordonii}

To identify BfrAB-regulated genes in S. gordonii, a transcriptome analysis was performed for $S$. gordonii V288 wild-type and two $b f r$-negative mutants using a custom Affymetrix GeneChip microarray. Two bfr $A B$ mutants, an insertional mutant (MG288-1015) (Zhang et al., 2004) and a deletion mutant (V288bfr ${ }^{-}$) constructed for this study, were utilized to ensure that any genes identified as differentially regulated were not specific to either mutant. For DNA microarray assays, RNA was extracted from early stationary phase cells, because at this phase the bfrA promoter exhibits higher activity than during exponential phase (Zhang et al., 2004). Seven putative genes (designated $b f r C, b f r D, b f r E, b f r F, b f r G, b f r H$ and $b f r X$; Table 2) were expressed at lower levels in both mutants compared with the wild-type S. gordonii V288. Since the altered expression of these genes was not specific to either $b f r$ mutant, their reduced expression levels more probably resulted from the impaired functions of $b f r A B$. These genes, therefore, were selected for further characterization in this study. 
Table 2. Genes differentially expressed in the S. gordonii V288 wild-type and the $\mathrm{Bfr}^{-}$mutants

Gene name: function (GenBank accession no.; microarray probe ID)
bfrC: ABC transporter, ATP-binding protein (ABV10088; SG1561) bfrD: unknown (ABV09959; SG1560)

bfrE: ABC transporter, ATP-binding protein (ABV11086; SG1564)

bfrF: unknown (ABV10645; SG1563)

bfrG: unknown (ABV10185; SG1562)

bfrH: CAAX amino-terminal protease family protein (ABV10380; SG0950)

bfrX: ABC transporter, ATP-binding protein (ABV09881; SG1558)
Fold-change in gene expression relative to V288 wild-type

\begin{tabular}{|cc|}
$\begin{array}{c}\text { Fold-change in gene expression relative to V288 } \\
\text { wild-type }\end{array}$ \\
\hline V288 $\boldsymbol{b} f \boldsymbol{r}^{-}$ & MG288-1015 \\
-8.9 & -5.5 \\
-8.7 & -6.7 \\
-11.7 & -6.3 \\
-12.2 & -8.9 \\
-12.6 & -9.8 \\
-3.4 & -4.9 \\
-3.0 & -4.4 \\
\hline
\end{tabular}

The chromosomal location of the $b f r H$ gene, which encodes a CAAX amino-terminal protease family protein, is remote from the $b f r$ locus (Fig. 1). The other six genes are located immediately downstream of $b f r A B$ (Fig. 1) and are transcribed in the direction opposite to $b f r A B$. The $b f r C$ and $b f r D$ sequences are separated by a 12 bp intergenic sequence, which suggested that $b f r C$ and $b f r D$ were cotranscribed as an operon. The co-transcription of $b f r C$ and $b f r D$ was confirmed by RT-PCR (data not shown). The $b f r E$ and $b f r F$ sequences are separated by a 16 bp intergenic sequence, and $b f r F$ and $b f r G$ are separated by a 37 bp intergenic sequence. The co-transcription of $b f r E F$ and $b f r F G$ was also confirmed by RT-PCR (data not shown). Thus, $b f r E F G$ forms a three-gene operon. Similarly, $b f r X$ and its immediate downstream gene, $b f r Y$, are separated by a 6 bp intergenic sequence, and are co-transcribed (data not shown). Protein sequence analysis suggested that $b f r X Y, b f r C D$ and $b f r E F G$ encoded three putative $\mathrm{ABC}$ transporters. Among these genes, $b f r X, b f r C$ and $b f r E$ encode three Walker motif-containing ATP-binding proteins with high similarities; $b f r Y, b f r D, b f r F$ and $b f r G$ encode four homologous transmembrane polypeptides. Bioinformatic analysis using the SOSUI server (http://bp.nuap.nagoya-u.ac.jp/sosui/) predicts that $\mathrm{BfrH}$, BfrY, BfrD, BfrF and BfrG each contain six transmembrane helices.

\section{S. gordonii}

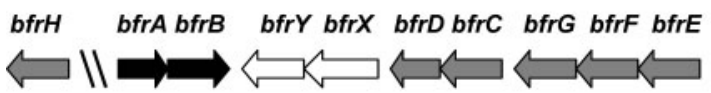

\section{S. sanguinis}

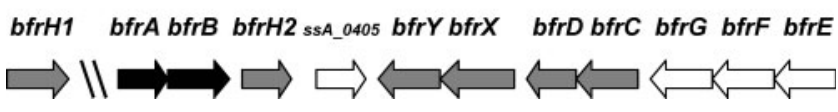

Fig. 1. Genetic loci regulated by $B f r A B$ and $B f r A B$ ss. Grey arrows, genes regulated by $B f r A B / B f r A B_{s s}$ systems based on data from this study; white arrows, genes not regulated by $B f r A B / B f r A B$ ss systems based on data from this study.
To validate the data from DNA microarray experiments, semiquantitative RT-PCR experiments were performed. In agreement with the data from the DNA microarray results, the RT-PCR experiments showed that the $S$. gordonii V288bfr ${ }^{-}$strain expressed lower levels of $b f r C D, b f r E F G$ and $b f r H$ than the wild-type (Fig. 2a). However, the decreased expression of $b f r X$ in $S$. gordonii $\mathrm{V} 288 b f r^{-}$seen in DNA microarray analysis was not observed using semiquantitative RT-PCR (Fig. 2a).

To determine whether the altered expression of $b f r C D$, $b f r E F G$ and $b f r H$ was directly associated with the inactivation of the BfrAB TCS, a strain complemented for the deletion of $b f r$ was constructed by transforming the V288bfr ${ }^{-}$strain with the shuttle vector pDL276 harbouring the $b f r A B$ operon. The expression levels of $b f r C D, b f r E F G$ and $b f r H$ were largely restored in the complementary strain $\mathrm{V}^{288} \mathrm{bfr}^{+}$(Fig. 2a), indicating that BfrAB is involved in the regulation of these genes.

\section{Identification of BfrAB-homologous TCSs in S. sanguinis}

Using the BLASTP program (Altschul et al., 1997; Schaffer et al., 2001), we searched the nonredundant sequence database (http://www.ncbi.nlm.nih.gov) using BfrA and BfrB protein sequences to find Bfr-homologous TCSs in other bacterial species. The S. sanguinis TCS of SSA_0401$0402\left(\mathrm{Bfr}_{\mathrm{AB}}\right)$ showed the highest similarity ( 90\%) to $B f r A B$. In addition, the $S$. sanguinis genome contains genes homologous to BfrC, BfrD, BfrE, BfrF, BfrG, BfrH, BfrX and BfrY.

As in S. gordonii, the bfrH-homologous gene ssA_0253 $\left(b f r H 1_{s s}\right)$ in $S$. sanguinis was outside the $b f r$-homologous locus (Fig. 1). However, $b f r A B_{s s}$ is immediately followed by $s s A \_0403\left(b f r H 2_{s s}\right)$, which encodes another CAAX aminoterminal protease family protein, and $s s A \_0405$, which encodes a xenobiotic response element (XRE) family transcriptional regulator (Fig. 1). The XRE family proteins interact with cognate DNA sequences through their helixturn-helix (HTH) motifs. Both $b f r H 2_{s s}$ and $s s A \_0405$ have their own putative promoters, which were identified using the program 'Neural Network Promoter Prediction' 
(a)

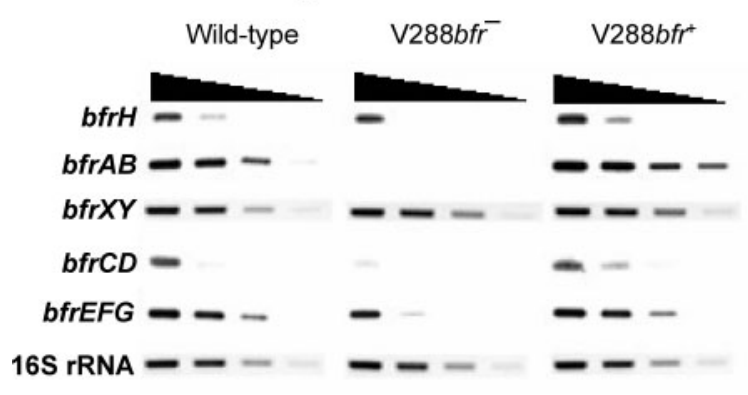

(b)

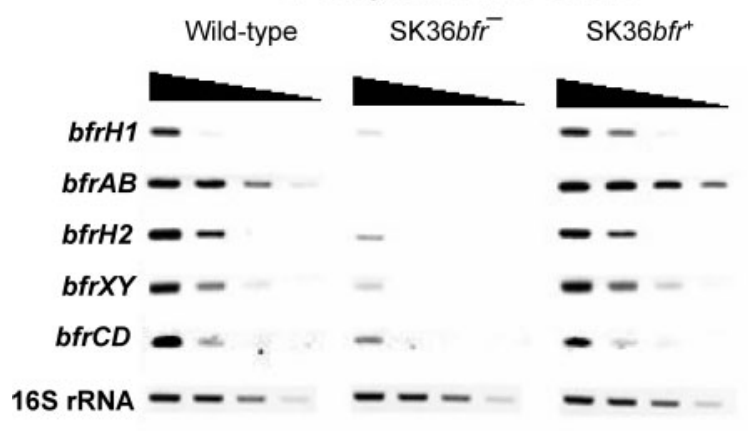

Fig. 2. Semiquantitive RT-PCR of selected genes. (a) Expression of selected genes in S. gordonii V288 wild-type, V288 $\mathrm{ffr}^{-}$and

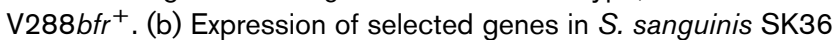
wild-type, SK36 $\mathrm{ffr}^{-}$and SK36 bfr ${ }^{+}$. The 16S rRNA gene was used as an internal control for RT-PCR. Fourfold serial dilutions (represented by the declining slopes of the triangles) of cDNAs were used as PCR templates to amplify the indicated transcripts. All data shown are representative of two independent experiments.

(http://www.fruitfly.org/seq_tools/promoter.html), and are transcribed in the same direction as the $b f r A B_{s s}$ operon. Three $\quad b f r C D / b f r E F G / b f r X Y$-homologous operons, ssA_0407-0406 (bfrXY $\left.Y_{s s}\right)$, ssA_0409-0408 $\left(b f r C D_{s s}\right)$ and ssA_0412-0411-0410 (bfrEFG $\left.G_{s s}\right)$, are located in close proximity downstream of $s s A \_0405$ and transcribed in the opposite direction (Fig. 1). The co-transcription of $b f r X_{\mathrm{ss}} / b f r Y_{\mathrm{ss}}, b f r C_{s s} / b f r D_{s s}$ and $b f r E_{s s} / b f r F_{s s} / b f r G_{s s}$ was confirmed by RT-PCR (data not shown).

\section{Identification of genes regulated by TCS BfrAB in S. sanguinis}

The high similarity of the protein sequences between $\mathrm{Bfr} A \mathrm{~B}$ in $S$. gordonii and $\mathrm{BfrAB}_{\mathrm{ss}}$ in $S$. sanguinis suggests that the functions of the TCSs might be conserved in the two species. To identify genes regulated by $\mathrm{BfrAB}_{\text {ss }}$ in $S$. sanguinis, we constructed a deletion mutant by allelic exchange. The expression of a set of selected genes was first compared between the $b f r A B_{s s}$ deletion mutant strain $\left(\mathrm{SK} 36 \mathrm{bfr}^{-}\right.$) and the S. sanguinis wild-type. SK36bfr expressed $b f r H 1_{s s}, b f r H 2_{s s}$ and the two operons $b f r X Y_{s s}$ and $b f r C D_{s s}$ at substantially lower levels than the wild-type (Fig. 2b). However, the expression levels of ssA_0405 and the operon $b f r E F G_{s s}$ were similar between SK36ffr ${ }^{-}$and the parent wild-type strain (data not shown). Furthermore, we constructed a complemented strain for SK36 bfr ${ }^{-}$to confirm that the altered expression of these genes was the direct result of inactivation of the $\mathrm{BfrAB}_{\mathrm{ss}}$ TCS. The expression levels of $b f r H 1_{s s}, b f r H 2_{s s}$ and of the operons $b f r X Y_{s s}$ and $b f r C D_{s s}$ were restored in the complementary strain SK36bfr ${ }^{+}$(Fig. 2b), indicating that the BfrAB $\mathrm{Bs}_{\mathrm{ss}}$ TCS is involved in the regulation of these genes in S. sanguinis.

\section{Binding of the BfrA DNA-binding domain to the upstream promoter-containing regions of BfrAB- regulated genes in vitro}

The response regulator BfrA is comprised of two conserved domains, an $\mathrm{N}$-terminal signal receiver domain (amino acid residues 5-116) and a C-terminal DNA-binding domain (residues 129-223). Our results indicated that $\mathrm{BfrAB}$ is involved in the regulation of multiple genes in $S$. gordonii. We then examined whether BfrA could bind to the upstream promoter-containing regions of these genes, thus directly controlling their transcription activities. First, a fusion protein ( $\left.\mathrm{His}_{6} \mathrm{DBBfr} \mathrm{A}\right)$, including a $\mathrm{C}$-terminal fragment of the BfrA protein (DBBfrA, amino acids 118226) and an N-terminal $6 \times$ histidine tag, was overexpressed in E. coli and purified. The interactions of the purified $\mathrm{His}_{6} \mathrm{DBBfrA}$ with the upstream promoter-containing regions of selected genes were then tested by EMSA.

Purified $\mathrm{His}_{6} \mathrm{DBBfrA}$ bound to the upstream promotercontaining regions of $b f r C D, b f r E F G$ and $b f r H$ as shown by EMSA (Fig. 3). In contrast, $\mathrm{His}_{6} \mathrm{DBBfr} A$ protein could not bind to the upstream promoter-containing regions of the $S$. gordonii sthAB operon (Fig. 3) or comCDE operon (data not shown). Since BfrA and its $S$. sanguinis counterpart $\mathrm{BfrA}_{\mathrm{ss}}$ share high similarity (Fig. 4), we tested the interactions of $\mathrm{His}_{6} \mathrm{DBBfrA}$ with the upstream promotercontaining regions of $\mathrm{BfrAB}_{\mathrm{ss}}$-regulated genes in $S$. sanguinis. $\mathrm{His}_{6} \mathrm{DBB}$ frA bound to the upstream promotercontaining regions of $b f r X Y_{s s}, b f r C D_{s s}$ and $b f r H 1_{s s}$ (Fig. 3). His $_{6}$ DBBfrA, however, did not bind to the upstream promoter-containing regions of $b f r H 2_{s s}$ (Fig. 3). In addition, binding to $\mathrm{His}_{6} \mathrm{DBBfrA}$ by the promoter-containing regions of $b f r C D, b f r E F G, b f r H, b f r X Y_{s s}, b f r C D_{s s}$ and $b f_{r} \mathrm{H}_{s s}$ was $\mathrm{His}_{6} \mathrm{DBBfrA}$ dose-dependent in all cases (Fig. 3 ), which also suggested that $\mathrm{His}_{6} \mathrm{DBBfrA}$ interacted selectively with these six promoter-containing regions.

\section{Identification of the DNA motif recognized by BfrA}

To identify the potential DNA motif recognized by BfrA, we aligned the upstream promoter-containing regions of $b f r H, b f r C, b f r E, b f r X Y_{s s}, b f r C D_{s s}$ and $b f r H 1_{s s}$ (Fig. 5). A 24 bp conserved DNA motif with a consensus sequence of 

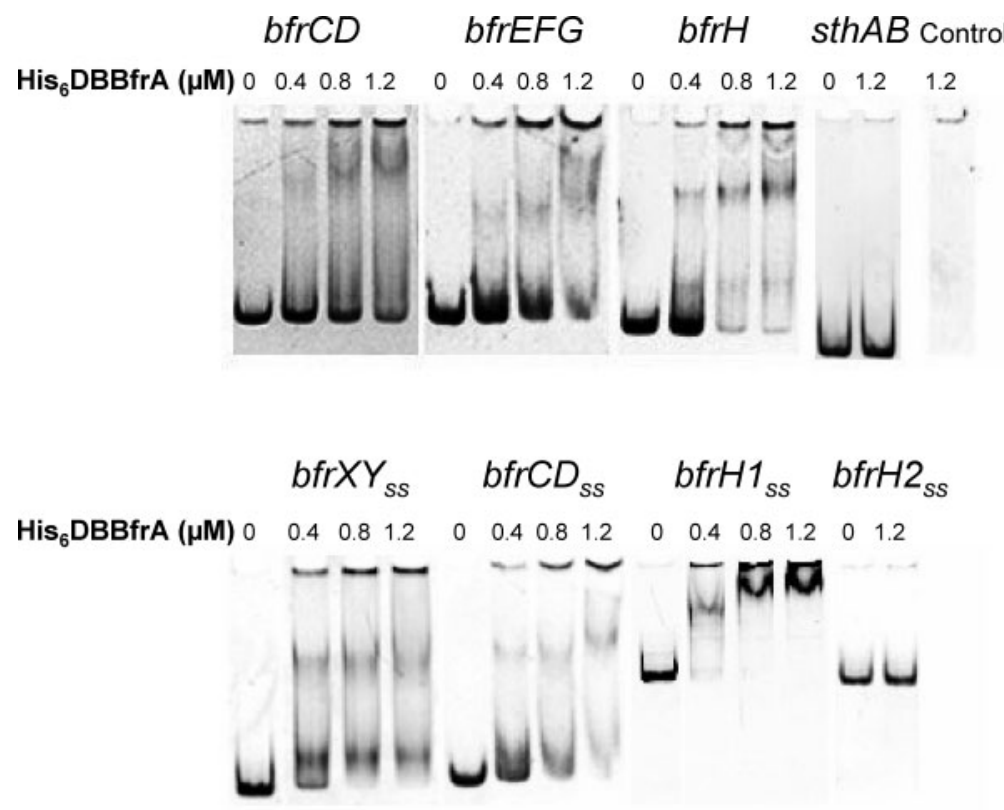

Fig. 3. Non-isotopic EMSA of binding of $\mathrm{His}_{6}$ DBBfrA to the upstream promoter-containing regions of selected genes. The upstream promoter-containing regions of the selected genes were amplified by PCR, purified and used to test the interactions with varying amounts of purified $\mathrm{His}_{6} \mathrm{DBBfrA}$. The reaction mixtures were separated on $5 \%$ nondenaturing polyacrylamide gels, stained with SYBR Green and visualized using a $314 \mathrm{~nm}$ UV transilluminator. Control, $\mathrm{His}_{6} \mathrm{DBBfr} \mathrm{A}$ protein-only control.

TTTCTTTAGAAATATTTTAGAATT was identified. This conserved motif contains two direct repeats of TTTAGAA, which are separated by a $4 \mathrm{bp}$ intervening sequence. This $24 \mathrm{bp}$ conserved motif is not found in the upstream promoter-containing regions of $b f r H 2_{s s}$, or the $S$. gordonii sth $A B$ and comCDE operons. As described above, the upstream promoter-containing regions of $b f r H 2_{s s}$, and the $S$. gordonii sth $A B$ and comCDE operons were not recognized by $\mathrm{His}_{6}$ DBBfrA.

Purified $\mathrm{His}_{6}$ DBBfrA protein could bind to and retard the mobility of the $24 \mathrm{bp}$ conserved DNA motif found in bfrCD (Fig. 6a, lane 2). In contrast, an 18 bp DNA fragment, TTTAGAAATATTTTAGAA, which is located in the $24 \mathrm{bp}$ conserved motif and includes the two direct repeats of TTTAGAA and a $4 \mathrm{bp}$ intervening sequence, could not complex with $\mathrm{His}_{6}$ DBBfrA (Fig. 6b, lane 2). The presence of excess unlabelled $24 \mathrm{bp}$ conserved DNA motif could effectively inhibit the $\mathrm{His}_{6} \mathrm{DBBfrA}$-mediated gel shift (Fig. 6a, lane 3). However, the presence of the excess unlabelled 18 bp DNA fragment had no effect on the complex formation of $\mathrm{His}_{6} \mathrm{DBBfrA}$ and the $24 \mathrm{bp}$ DNA motif (Fig. 6a, lane 4). Similarly, purified $\mathrm{His}_{6}$ DBBfrA protein could interact with the $24 \mathrm{bp}$ conserved DNA motifs found in bfrEFG (Fig. 6c) and $b f r H$ (Fig. 6d). These results suggested that $\mathrm{His}_{6} \mathrm{DBBfrA}$ could specifically recognize this 24 bp conserved DNA motif.

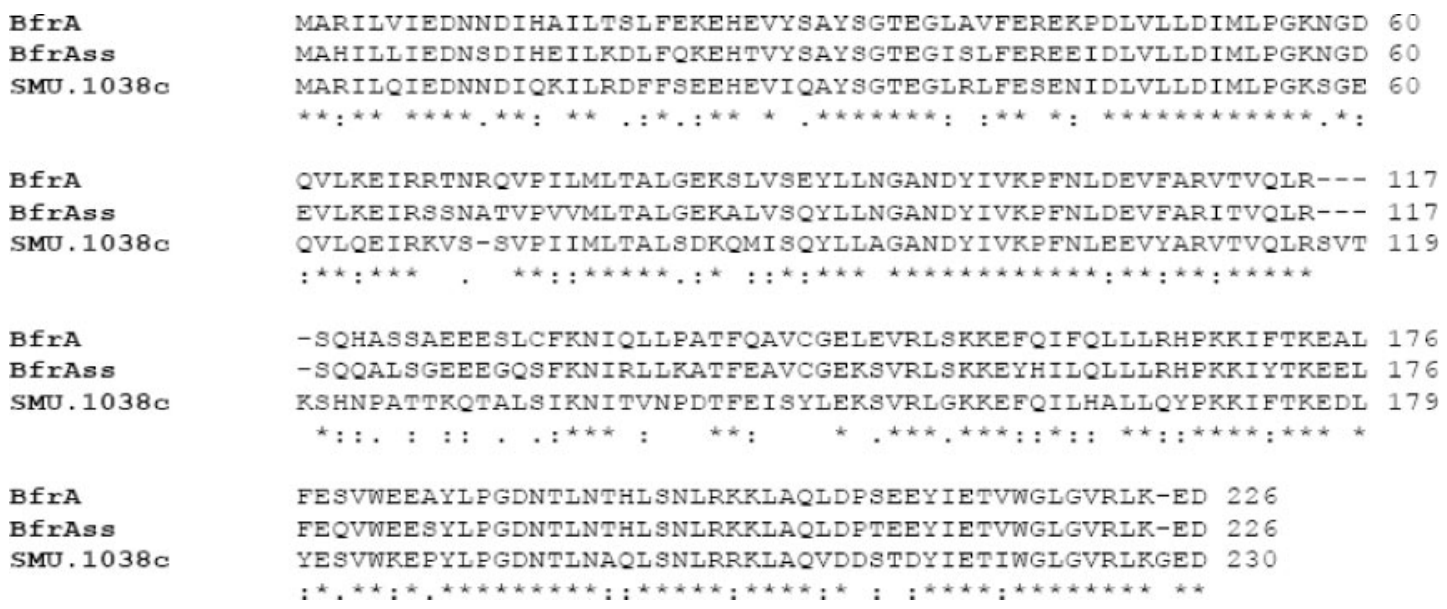

Fig. 4. Comparison of the primary sequences of BfrA, BfrAss and SMU.1038c. S. gordonii BfrA and homologous genes in S. sanguinis $\left(\mathrm{Bfr}_{\mathrm{ss}}\right.$ ) and $S$. mutans (SMU.1038c) were aligned using CLUSTALW2 (http://www.ebi.ac.uk/Tools/clustalw2/ index.html). '*', ':' and '.' represent identical residues, highly conserved residues and weakly conserved residues, respectively. 


PbfrC
PbfrCss
PbfrH
PbfrH1ss
PbfrXss
PbfrE
PbfrC
PbfrCss
PbfrH
PbfrH1ss
PbfrXss
PbfrE
PbfrC
PbfrCss
PbfrH
PbfrH1ss
PbfrXss
PbfrE

ATATACAGAGTTAGTCCCTGACTAGCTCTTTT-TGTTTGTCTTTGTATTTC-G--TATTT 56 ATTTAAGCAGTCAGCCCTTTGGCTGCTTTTTTATTGCTTTTGGATTGATTCTG--CATTT 58 GGCAAGAAAATGGAAGCAGTAAAAATCTTGGGTTT-TATACCTTTAAAATCTC-TTTTTT 58 AGCAAACAAGTTGAAGTGGCGATAATCCTTGATTTGTTTATGTTTATAATTTCTTTCATT 60 ----AAACAATGAGCTGGTTCTTGACTGGCTCATTTTAATCTTTTCAATTTT--AAATTT 54 ACACAAGCTAGATATAACTGAAAAATTTCTGCTATTTGCAGGAATTTTTTTGCTAAAAAA 60

CTTTAGAAATACTTTAAAAAGACTTGAGAAATATTTTAAATTTAGTTTGTATACTT-TAG 115 CTTTAGAAATATTTTAGAATTTCTTGAGAAATATTTGAAATCTAGCTTGTATACTA-AAA 117 CTTTAGAAACATTTTAGAATTACTTAATAAATAATTGAAGTTTGCTTTATATAATG-ATG 117 CTTTAGAAATATTTTAGAATTACTTTATAAATTCTTGAAGTTTGTCTTGTATAATC-ATA 119 CTTTAGAAATATTTTAGAATTTCTTGAGAAATATTTGAAATTTAGTTTGTATACTA-AAA 113 CTTTAGAAATATTTTAGAAATGCTTGAGAATTATTTGAAAGATTGGTACTATACTGGATA 120

TTA--AACCTAA--GAAAGCGAGAA-TATGCT--------------ATG 145
TCA--AACCTAG--GAAAGCGAGAA-TATACC-------------ATG 147
GTA--AAGAAAT--GAGAGAAAGGAG-TTTCTA-------------ATG 148
TTA--AAGAAA------AGAAAGGAG-TCTCTTATC----------ATG 149
GTATAAACAAAG-TAATTAAAGGAGAAACATC------------ATG 147
GTGAAAAGAGAGCTTCCTCTCCCTATCTATACAAGGAGACTCATCATG 169

Fig. 5. Alignment of the $\mathrm{His}_{6} \mathrm{DBBfrA}$-recognized promoter sequences. His ${ }_{6} \mathrm{DBBfr} A$ binds to the upstream regulatory regions of $b f r C, b f r E, b f r H, b f r C_{s s}, b f r H 1_{\text {ss }}$ and $b f r X_{s s}$. To identify the potential common motif recognized by His ${ }_{6}$ DBBfrA, the upstream regulatory regions of $b f r C, b f r E, b f r H, b f r C_{s s}, b f r H 1_{\text {ss }}$ and $b f r X_{s s}$ were aligned using CLUSTALW2 (http://www.ebi.ac.uk/Tools/ clustalw2/index.html). The conserved 24 bp DNA motif among these regulatory regions is underlined. The specific interaction between $\mathrm{His}_{6} \mathrm{DBBfr}$ a and this conserved 24 bp DNA motif was then confirmed by EMSA (Fig. 6). ATG in bold type indicates the start codon.

\section{DISCUSSION}

We have previously identified a putative TCS, BfrAB, which is involved in the development of oral biofilms. To further characterize the functions of this system, efforts were made in

(a)

(b) (c)

(d)

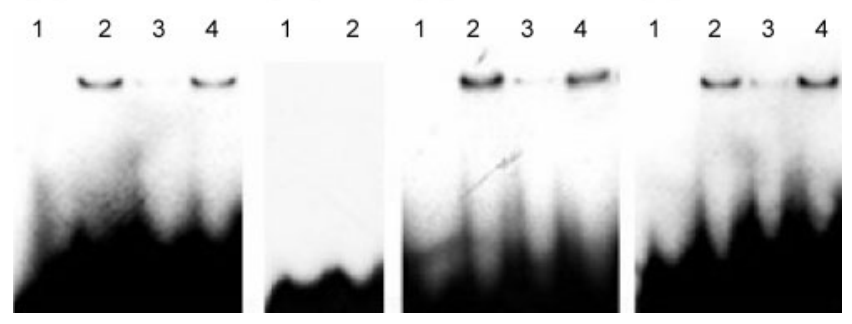

Fig. 6. EMSA to identify the DNA motif recognized by $\mathrm{His}_{6}$ DBBfrA. ${ }^{32} \mathrm{P}$-labelled probes were mixed with purified $\mathrm{His}_{6} \mathrm{DBBfr}$, incubated and separated on $8 \%$ non-denaturing polyacrylamide gels. The gel was visualized by autoradiography. (a) ${ }^{32} \mathrm{P}$-labelled 24 bp conserved DNA motif of bfrCD. (b) ${ }^{32} \mathrm{P}$ labelled $18 \mathrm{bp}$ DNA fragment containing two direct repeats of TTTAGAA. (c) ${ }^{32} \mathrm{P}$-labelled $24 \mathrm{bp}$ conserved DNA motif of bfrEFG. (d) ${ }^{32} \mathrm{P}$-labelled $24 \mathrm{bp}$ conserved DNA motif of $b f r H$. Lanes: 1 , reaction mixtures containing ${ }^{32} \mathrm{P}$-labelled probe alone; 2 , ${ }^{32} \mathrm{P}$-labelled probe with purified $\mathrm{His}_{6} \mathrm{DBBfrA}$ protein; $3,{ }^{32} \mathrm{P}$ labelled probe with purified $\mathrm{His}_{6} \mathrm{DBBfr} A$ protein and excess unlabelled probe; $4,{ }^{32} \mathrm{P}$-labelled probe with purified $\mathrm{His}_{6} \mathrm{DBBfr} A$ protein and excess of unlabelled $18 \mathrm{bp}$ DNA fragment containing two direct repeats of TTTAGAA. this study to identify the genes regulated by BfrAB in $S$. gordonii. As shown by DNA microarray analysis and confirmed by RT-PCR, six genes were downregulated in two $b f r A B$ mutants when compared with $S$. gordonii wild-type.

Among the genes regulated by $b f r A B$ in $S$. gordonii, bfrCD and $b f r E F G$ encode two homologous $\mathrm{ABC}$ transporters. $\mathrm{BfrC}$ and BfrE are putative ATP-binding proteins, and $\mathrm{BfrD}, \mathrm{BfrF}$ and $\mathrm{BfrG}$ are putative transmembrane proteins. $\mathrm{ABC}$ transporters exist in all species (Decottignies \& Goffeau, 1997; Holland \& Blight, 1999), and serve to transport substrates across the cell membrane, driven by energy from ATP hydrolysis. The typical ABC transporter comprises two hydrophilic domains, which bind and hydrolyse ATP to facilitate the transportation process, and two hydrophobic domains, which translocate the substrate across the membrane and may determine substrate specificity (Higgins, 1992; Jones \& George, 2004). An ABC transporter can be composed of homoor heterodimers of ATP-binding domains and membranespanning domains. In bacteria, these domains are often produced as separate polypeptides (Higgins, 1992). BfrD, BfrF and BfrG all contain six membrane-spanning segments, the structure that typically characterizes these transmembrane domains/polypeptides. Another gene regulated by $\mathrm{BfrAB}, b f r H$, encodes a CAAX amino-terminal protease family protein. Members of this protein family are grouped based on the sequence alignment, and are putative membrane-bound metalloproteases (Pei \& Grishin, 2001).

$\mathrm{BfrC}$ and BfrE share a high degree of homology with the members of the BcrA subfamily $\mathrm{ABC}$ transporters. The 
$\mathrm{ABC}$ transporter $\mathrm{BcrABC}$ is responsible for the bacitracin resistance of Bacillus licheniformis (Podlesek et al., 1995). $\mathrm{BcrA}$ is an ATP-binding protein, and $\mathrm{BcrB}$ and $\mathrm{BcrC}$ are integral membrane proteins. $\mathrm{BfrD}, \mathrm{BfrF}$ and $\mathrm{BfrG}$, however, do not share high homology with $\mathrm{BcrB}$ and $\mathrm{BcrC}$ or other proteins with known functions. Since BfrCD, BfrEFG and $\mathrm{BfrH}$, a putative membrane protease, are all regulated by $B$ frAB, we speculate that these membrane components are involved in the transport of some proteins/peptides, which may be required by $S$. gordonii for biofilm development. $\mathrm{BfrH}$ may process the protein/peptides, while BfrCD and BfrEFG may be responsible for the transport.

The TCS with the highest similarity to S. gordonii BfrAB was identified in S. sanguinis. As reported previously (Zhang et al., 2004), another TCS (SMU.1038c-1037c) with significant similarity to $\mathrm{Bfr} A \mathrm{~B}$ has been identified in another oral streptococcus, $S$. mutans. In S. mutans, the counterpart of BfrAB, SMU.1038c-1037c, is involved in the regulation of a bfrCD-homologous operon, which is located directly downstream of smu.1038c-1037c (J. Kreth and others, unpublished data). The $S$. sanguinis chromosome encodes three operons for putative $\mathrm{ABC}$ transporters homologous to $b f r C D$ and $b f r E F G, b f r C D_{s s}, b f r E F G_{s s}$ and $b f r X Y_{s s}$. Among them, $b f r C D_{s s}$ and $b f r X Y_{s s}$ are regulated by $S$. sanguinis $\mathrm{BfrAB}_{\mathrm{ss}}$. These results suggest that the BfrAB-homologous systems are organized similarly in oral streptococci to regulate the conserved $\mathrm{ABC}$ transporters. We have previously reported that $S$. gordonii biofilm-associated cells express higher levels of $b f r A B$ than free-growing cells (Zhang et al., 2004). Furthermore, S. mutans sessile cells also express higher levels of bfrAB-homologous smu.1038c-1037c than free-growing cells (Shemesh et al., 2007). BfrAB-homologous systems, therefore, may be commonly involved in biofilm development by oral streptococci.

Two genes, $b f r H 1_{s s}$ and $b f r H 2_{s s}$, encoding CAAX aminoterminal protease family proteins are regulated by $B_{f r} A B_{s s}$ in $S$. sanguinis. Differing from $b f r H 1_{s s}$, the upstream promoter-containing region of $b f r H 2_{s s}$ cannot be recognized by $\mathrm{BfrA}$, suggesting that $\mathrm{BfrAB}_{\mathrm{ss}}$ does not directly regulate $b f r H 2_{s s}$ transcription. On the other hand, the reduced expression level of $b \mathrm{frH} 2_{s s}$ in the SK36bfr ${ }^{-}$strain is restored in the complemented strain SK36 bfr ${ }^{+}$, in which $b f r A B_{s s}$ is expressed in a shuttle vector. Hence, altered expression of $b f r H 2_{s s}$ in the SK36ffr ${ }^{-}$strain is unlikely to be caused by a polar effect of the disruption of $B_{f r A B}$. Further studies will clarify the mechanism by which $\mathrm{BfrAB}_{\mathrm{ss}}$ is involved in the regulation of $b f r H 2_{s s}$.

Dental plaque is initiated by the adherence of pioneer colonizers to saliva-coated tooth surfaces. Pioneer colonizers in the early plaque interact with and facilitate incorporation of later colonizers. Among the later colonizers, Porphyromonas gingivalis is implicated as a pathogen in periodontal infections, and can interact with $S$. gordonii (Brooks et al., 1997; Chung et al., 2000; Kuboniwa et al., 2006; Lamont et al., 2002; McNab et al., 2003; Park et al., 2005; Simionato et al., 2006). Interestingly, S. gordonii bfrC and $b f r G$ appear to be required for the maturation of dualspecies biofilms with P. gingivalis (Kuboniwa et al., 2006; $\mathrm{McNab}$ et al., 2003). We now plan to define the role of $\mathrm{BfrAB}$ in the development of $S$. gordonii-P. gingivalis biofilms.

In conclusion, we provide evidence that $b f r A B$ and $b f r A B$ homologous systems share common roles as regulators of the $\mathrm{ABC}$ transporters in $S$. gordonii and S. sanguinis. Studies are ongoing to identify the substrates transported by the $\mathrm{Bfr} A B$-regulated $\mathrm{ABC}$ transporters and to explore potential signals sensed by the BfrAB TCS. These data will provide valuable information for the molecular dissection of the regulatory pathways for development of oral streptococcal biofilms.

\section{ACKNOWLEDGEMENTS}

This work was supported by NIH grant R01 DE08590, and J. N. E. was supported by a short-term fellowship by T32DE007288 (MinnCResT program). We thank David Basi for suggestions about EMSA.

\section{REFERENCES}

Altschul, S. F., Madden, T. L., Schaffer, A. A., Zhang, J., Zhang, Z., Miller, W. \& Lipman, D. J. (1997). Gapped BLAST and PSI-BLAST: a new generation of protein database search programs. Nucleic Acids Res 25, 3389-3402.

Bayliss, R., Clarke, C., Oakley, C. M., Somerville, W., Whitfield, A. G. \& Young, S. E. (1983). The microbiology and pathogenesis of infective endocarditis. Br Heart J 50, 513-519.

Bhagwat, S. P., Nary, J. \& Burne, R. A. (2001). Effects of mutating putative two-component systems on biofilm formation by Streptococcus mutans UA159. FEMS Microbiol Lett 205, 225-230.

Brooks, W., Demuth, D. R., Gil, S. \& Lamont, R. J. (1997). Identification of a Streptococcus gordonii $\mathrm{SspB}$ domain that mediates adhesion to Porphyromonas gingivalis. Infect Immun 65, 3753-3758.

Brown, S. A. \& Whiteley, M. (2007). A novel exclusion mechanism for carbon resource partitioning in Aggregatibacter actinomycetemcomitans. J Bacteriol 189, 6407-6414.

Chung, W. O., Demuth, D. R. \& Lamont, R. J. (2000). Identification of a Porphyromonas gingivalis receptor for the Streptococcus gordonii SspB protein. Infect Immun 68, 6758-6762.

Decottignies, A. \& Goffeau, A. (1997). Complete inventory of the yeast ABC proteins. Nat Genet 15, 137-145.

Dorel, C., Vidal, O., Prigent-Combaret, C., Vallet, I. \& Lejeune, P. (1999). Involvement of the Cpx signal transduction pathway of E. coli in biofilm formation. FEMS Microbiol Lett 178, 169-175.

Dunny, G. M., Lee, L. N. \& LeBlanc, D. J. (1991). Improved electroporation and cloning vector system for Gram-positive bacteria. Appl Environ Microbiol 57, 1194-1201.

Fournier, B. \& Hooper, D. C. (2000). A new two-component regulatory system involved in adhesion, autolysis, and extracellular proteolytic activity of Staphylococcus aureus. J Bacteriol 182, 3955-3964.

Frandsen, E. V., Pedrazzoli, V. \& Kilian, M. (1991). Ecology of viridans streptococci in the oral cavity and pharynx. Oral Microbiol Immunol 6, 129-133.

Hancock, L. E. \& Perego, M. (2004). The Enterococcus faecalis $f$ sr twocomponent system controls biofilm development through production of gelatinase. J Bacteriol 186, 5629-5639. 
Havarstein, L. S., Gaustad, P., Nes, I. F. \& Morrison, D. A. (1996). Identification of the streptococcal competence-pheromone receptor. Mol Microbiol 21, 863-869.

Herzberg, M. C. (1996). Platelet-streptococcal interactions in endocarditis. Crit Rev Oral Biol Med 7, 222-236.

Higgins, C. F. (1992). ABC transporters: from microorganisms to man. Annu Rev Cell Biol 8, 67-113.

Holland, I. B. \& Blight, M. A. (1999). ABC-ATPases, adaptable energy generators fuelling transmembrane movement of a variety of molecules in organisms from bacteria to humans. J Mol Biol 293, 381-399.

Jones, P. M. \& George, A. M. (2004). The ABC transporter structure and mechanism: perspectives on recent research. Cell Mol Life Sci $\mathbf{6 1}$, 682-699.

Kilian, M. \& Holmgren, K. (1981). Ecology and nature of immunoglobulin A1 protease-producing streptococci in the human oral cavity and pharynx. Infect Immun 31, 868-873.

Kuboniwa, M., Tribble, G. D., James, C. E., Kilic, A. O., Tao, L., Herzberg, M. C., Shizukuishi, S. \& Lamont, R. J. (2006). Streptococcus gordonii utilizes several distinct gene functions to recruit Porphyromonas gingivalis into a mixed community. Mol Microbiol 60, 121-139.

Lamont, R. J., El-Sabaeny, A., Park, Y., Cook, G. S., Costerton, J. W. \& Demuth, D. R. (2002). Role of the Streptococcus gordonii SspB protein in the development of Porphyromonas gingivalis biofilms on streptococcal substrates. Microbiology 148, 1627-1636.

Li, Y. H., Lau, P. C., Tang, N., Svensater, G., Ellen, R. P. \& Cvitkovitch, D. G. (2002). Novel two-component regulatory system involved in biofilm formation and acid resistance in Streptococcus mutans. J Bacteriol 184, 6333-6342.

Loo, C. Y., Corliss, D. A. \& Ganeshkumar, N. (2000). Streptococcus gordonii biofilm formation: identification of genes that code for biofilm phenotypes. J Bacteriol 182, 1374-1382.

Lunsford, R. D. (1998). Streptococcal transformation: essential features and applications of a natural gene exchange system. Plasmid 39, 10-20.

Macrina, F. L., Evans, R. P., Tobian, J. A., Hartley, D. L., Clewell, D. B. \& Jones, K. R. (1983). Novel shuttle plasmid vehicles for EscherichiaStreptococcus transgeneric cloning. Gene 25, 145-150.

Manford, M., Matharu, J. \& Farrington, K. (1992). Infective endocarditis in a district general hospital. J R Soc Med 85, 262-266.

McNab, R., Ford, S. K., El-Sabaeny, A., Barbieri, B., Cook, G. S. \& Lamont, R. J. (2003). LuxS-based signaling in Streptococcus gordonii: autoinducer 2 controls carbohydrate metabolism and biofilm formation with Porphyromonas gingivalis. J Bacteriol 185, 274-284.

Nambu, Y., Sugai, M., Gonda, H., Lee, C. G., Katakai, T., Agata, Y., Yokota, Y. \& Shimizu, A. (2003). Transcription-coupled events associating with immunoglobulin switch region chromatin. Science 302, 2137-2140.

Nobbs, A. H., Vajna, R. M., Johnson, J. R., Zhang, Y., Erlandsen, S. L., Oli, M. W., Kreth, J., Brady, L. J. \& Herzberg, M. C. (2007). Consequences of a sortase A mutation in Streptococcus gordonii. Microbiology 153, 4088-4097.

Nyvad, B. \& Kilian, M. (1987). Microbiology of the early colonization of human enamel and root surfaces in vivo. Scand J Dent Res 95, 369-380.

Nyvad, B. \& Kilian, M. (1990). Comparison of the initial streptococcal microflora on dental enamel in caries-active and in caries-inactive individuals. Caries Res 24, 267-272.

Otto, K. \& Silhavy, T. J. (2002). Surface sensing and adhesion of Escherichia coli controlled by the Cpx-signaling pathway. Proc Natl Acad Sci U S A 99, 2287-2292.

Palmer, K. L., Mashburn, L. M., Singh, P. K. \& Whiteley, M. (2005). Cystic fibrosis sputum supports growth and cues key aspects of Pseudomonas aeruginosa physiology. J Bacteriol 187, 5267-5277.
Park, Y., Simionato, M. R., Sekiya, K. \& other authors (2005). Short fimbriae of Porphyromonas gingivalis and their role in coadhesion with Streptococcus gordonii. Infect Immun 73, 3983-3989.

Parkins, M. D., Ceri, H. \& Storey, D. G. (2001). Pseudomonas aeruginosa GacA, a factor in multihost virulence, is also essential for biofilm formation. Mol Microbiol 40, 1215-1226.

Pei, J. \& Grishin, N. V. (2001). Type II CAAX prenyl endopeptidases belong to a novel superfamily of putative membrane-bound metalloproteases. Trends Biochem Sci 26, 275-277.

Podlesek, Z., Comino, A., Herzog-Velikonja, B., Zgur-Bertok, D., Komel, R. \& Grabnar, M. (1995). Bacillus licheniformis bacitracinresistance $\mathrm{ABC}$ transporter: relationship to mammalian multidrug resistance. Mol Microbiol 16, 969-976.

Prigent-Combaret, C., Vidal, O., Dorel, C. \& Lejeune, P. (1999). Abiotic surface sensing and biofilm-dependent regulation of gene expression in Escherichia coli. J Bacteriol 181, 5993-6002.

Rosan, B. \& Lamont, R. J. (2000). Dental plaque formation. Microbes Infect 2, 1599-1607.

Sambrook, J., Fritsch, E. F. \& Maniatis, T. (1989). Molecular Cloning: a Laboratory Manual, 2nd edn. Cold Spring Harbor, NY: Cold Spring Harbor Laboratory.

Schaffer, A. A., Aravind, L., Madden, T. L., Shavirin, S., Spouge, J. L., Wolf, Y. I., Koonin, E. V. \& Altschul, S. F. (2001). Improving the accuracy of PSI-BLAST protein database searches with compositionbased statistics and other refinements. Nucleic Acids Res 29, 29943005.

Shemesh, M., Tam, A. \& Steinberg, D. (2007). Differential gene expression profiling of Streptococcus mutans cultured under biofilm and planktonic conditions. Microbiology 153, 1307-1317.

Simionato, M. R., Tucker, C. M., Kuboniwa, M., Lamont, G., Demuth, D. R., Tribble, G. D. \& Lamont, R. J. (2006). Porphyromonas gingivalis genes involved in community development with Streptococcus gordonii. Infect Immun 74, 6419-6428.

Socransky, S. S., Haffajee, A. D., Cugini, M. A., Smith, C. \& Kent, R. L., Jr (1998). Microbial complexes in subgingival plaque. J Clin Periodontol 25, 134-144.

Stock, A. M., Robinson, V. L. \& Goudreau, P. N. (2000). Twocomponent signal transduction. Annu Rev Biochem 69, 183-215.

Tao, L. \& Herzberg, M. C. (1999). Identifying in vivo expressed streptococcal genes in endocarditis. Methods Enzymol 310, 109-116.

Terleckyj, B. \& Shockman, G. D. (1975). Amino acid requirements of Streptococcus mutans and other oral streptococci. Infect Immun 11, 656-664.

Terleckyj, B., Willett, N. P. \& Shockman, G. D. (1975). Growth of several cariogenic strains of oral streptococci in a chemically defined medium. Infect Immun 11, 649-655.

Toledo-Arana, A., Merino, N., Vergara-Irigaray, M., Debarbouille, M., Penades, J. R. \& Lasa, I. (2005). Staphylococcus aureus develops an alternative, ica-independent biofilm in the absence of the arlRS twocomponent system. J Bacteriol 187, 5318-5329.

Vickerman, M. M., lobst, S., Jesionowski, A. M. \& Gill, S. R. (2007). Genome-wide transcriptional changes in Streptococcus gordonii in response to competence signaling peptide. J Bacteriol 189, 7799-7807.

Zhang, Y., Lei, Y., Khammanivong, A. \& Herzberg, M. C. (2004). Identification of a novel two-component system in Streptococcus gordonii V288 involved in biofilm formation. Infect Immun 72, 3489-3494.

Zhang, Y., Lei, Y., Nobbs, A., Khammanivong, A. \& Herzberg, M. C. (2005). Inactivation of Streptococcus gordonii SspAB alters expression of multiple adhesin genes. Infect Immun 73, 3351-3357.

Edited by: R. J. Lamont 